\title{
A INFECÇÃO URINÁRIA E RESISTÊNCIA A ANTIBIÓTICOS: REFLEXÕES
}

Tânia De Lorenzi

Discente do Curso de Farmácia

Jane Mary Lafayette Neves Gelinski

Professora Doutora Curso de Farmácia

Mariê Scotegagna Chiavini

Farmacêutica pela Universidade do Oeste de Santa Catarina 


\section{Resumo}

As infecções do trato urinário (ITU's) são causadas mais comumente por bactérias da família Enterobacteriaceae, particularmente a Escherichia coli. As mulheres são mais frequentemente acometidas por ITU's. Nesta breve revisão, o objetivo foi realizar uma abordagem sobre ITU's, o uso de antibióticos e a resistência bacteriana a antimicrobianos. A resistência microbiana a antibióticos é uma preocupação constante, principalmente para os profissionais da área da saúde. Nesta revisão, verificou-se que a resistência bacteriana ainda continuará sendo um grande problema de saúde pública. Novos antimicrobianos precisam ser desenvolvidos para ampliar as possibilidades de cura de infecções recorrentes. No entanto, a resistência bacteriana é o grande desafio a ser vencido.

Palavras-chaves: Saúde. Cistite. Antibióticos.Trato Urinário.

\section{Abstract}

Urinary tract infections (UTI's) are most commonly caused by bacteria of the family Enterobacteriaceae, particularly Escherichia coli. Women are more often affected by UTI's. In this brief review the aim was to realize an approach on UTI's, the use of antibiotics and bacterial resistance to antimicrobials. Microbial resistance to antibiotics is a constant concern mainly for health professionals. In this review, we verify that bacterial resistance will continue to be a major public health concern. New antimicrobials must be developed to increase the chances of curing recurrent infections. However, bacterial resistance is the great challenge to be overcome.

Key-words: Health. Cystitis. Antibiotics. Urinary Tract. 


\section{Introdução}

A Antigamente, as pessoas já utilizavam substâncias naturais como tentativa para combater inúmeras enfermidades causadas por infecções bacterianas, mas não tinham resultados significativos, pois milhares de pessoas morriam anualmente (TAVARES, 2014). No entanto, o pesquisador Alexander Fleming mudou a história da medicina, desenvolvendo o primeiro antibiótico em 1928, a penicilina. Ele realizou as pesquisas utilizando Staphylococcus aureus e, ocasionalmente, essas tinham contato com o fungo Penicillium notatum, e o pesquisador observou que os micro-organismos não se desenvolviam na presença daquela espécie (PÊRA, 2015). A descoberta não foi valorizada e considerada sem aplicação imediata, por que não havia tecnologia adequada para cultivar o fungo em grande quantidade, separar o antibiótico do meio de cultura e purificá-lo (TAVARES, 2014). No entanto, a pesquisa de Fleming despertou interesse de outros, ainda em 1940. Tais pesquisadores conseguiram demonstrar que a substância descoberta não era tóxica ao hospedeiro, mas que matava os patógenos que causavam infecções. Iniciou-se a era dos antibióticos (TAVARES, 2014; RANG et al., 2012).

Os antibióticos são substâncias naturais extraídas a partir de fungos, bactérias, mas podem ser sintetizados (produzidos em indústrias farmacêuticas). A principal finalidade do antibiótico é prevenir ou tratar uma infecção causada por microorganismos (GUIMARÃES; MOMESSO; PUPO, 2010; MELO; DUARTE; SOARES, 2012).

Atualmente existem diversos antibióticos potentes contra os mais diferentes tipos de agentes infecciosos causadores de doenças, tais como: infecções do trato respiratório, do trato gastrointestinal, infecção urinária e entre outros (PERA, 2015). Conforme citado em vários trabalhos acadêmicos científicos, entre essas diversas patologias, a infecção urinária é uma das mais comuns e caracteriza-se por uma colonização e invasão de micro-organismos causando dano tecidual em qualquer parte do trato urinário, como rins, bexiga ou uretra (CUNHA; VEBER, 2011; KADOSAKI; SOUZA; BORGES, 2012; DUQUE, 2013).

Com a gigantesca utilização de antibióticos para o tratamento de infecções do trato urinário (ITUs), o desenvolvimento de resistência bacteriana tem se acentuado. Cada vez mais há dificuldades em erradicar essas infecções. Devido a essa resistência, 
ITUs são uma carga econômica substancial e um evidente problema de saúde pública. Portanto, novas estratégias de tratamento e medidas preventivas contra infecções do trato urinário, tais como, imunoestimulação ou imunomodulação para o desenvolvimento de vacinas ou medidas profiláticas são importantes para a saúde pública (NELIUS et al., 2013).

A resistência de micro-organismos a antibióticos é uma preocupação constante principalmente para os profissionais da área da saúde. Isso porque infecções hospitalares têm se tornado frequentes a cada ano, levando à superlotação dos hospitais, aumentando a administração de antibióticos repetidos e, assim, comprometendo o tratamento pela resistência bacteriana (PÊRA, 2015; CUNHA;VEBER, 2011).

\section{Desenvolvimento}

\section{OBJETIVOS}

Realizar uma revisão sistemática não extensa, mas suficiente para propiciar uma visão geral e reflexão sobre infecções urinárias e resistência a antibióticos.

\section{METODOLOGIA}

Nesta breve revisão são abordados os principais aspectos relacionados a infecções urinárias (ITU’s) em mulheres, o uso de antibióticos no tratamento de ITU's e resistência bacteriana. Foram consultadas pesquisas nas bases de dados constante principalmente do Portal de Periódicos da Capes (CAPES, 2018). Foram incluídas referências bibliográficas do ano 2000 até 2017. Os critérios de inclusão foram trabalhos que atendiam ao objetivo proposto e continham os termos: infecção urinária e mulheres, antibióticos, resistência bacteriana e Escherichia coli. Como critérios de exclusão estiveram todos os trabalhos cuja abordagem não atendia ao objetivo da pesquisa. 


\section{INFECÇÃO URINÁRIA E RESISTÊNCIA BACTERIANA}

Nesta revisão foram selecionadas vinte e cinco referências bibliográficas que atenderam ao objetivo proposto e incluíam os termos da pesquisa. O Quadro 1 resume as características principais dos trabalhos selecionados. 
QUADRO 1. Dados gerais do referencial bibliográfico utilizado após revisão sobre infecção urinária e resistência a antibióticos no período de 2005 a 2017

\begin{tabular}{|c|c|c|}
\hline Fonte Bibliográfica & Tipos de trabalhos & Temática \\
\hline $\begin{array}{l}\text { Dias et al., 2010; Drekonja; } \\
\text { Johnson,2008; Goll et al., 2013; } \\
\text { Guimarães et al., 2010; Kadosaki } \\
\text { et al., 2012; Moura; Fernandes, } \\
\text { 2010; Narciso, et al., 2011; Nelius, } \\
\text { et al., 2013; Oliveira et al., 2014; } \\
\text { Rodriguez et al., 2017; Reiz et al., } \\
\text { 2017; Roriz Filho et al., 2010; } \\
\text { Zhong et al., 2011. }\end{array}$ & Artigo científico & $\begin{array}{l}\text { Infecção do trato } \\
\text { urinário-ITU; } \\
\text { Resistência bacteriana, } \\
\text { antibióticoterapia e } \\
\text { profilaxia. }\end{array}$ \\
\hline $\begin{array}{l}\text { Almeida, 2014; Barberino, 2013; } \\
\text { Cunha; Veber, 2011; Duque, } \\
2013 .\end{array}$ & $\begin{array}{l}\text { Trabalhos de } \\
\text { conclusão de } \\
\text { curso, dissertação, } \\
\text { tese, monografia. }\end{array}$ & $\begin{array}{l}\text { Compostos bioativos e } \\
\text { antimicrobianos com } \\
\text { aplicação farmacêutica. } \\
\text { Resistência bacteriana. } \\
\text { Escherichia coli de ITU; }\end{array}$ \\
\hline $\begin{array}{l}\text { Rang et al., 2012; Tavares, 2014; } \\
\text { Tortora; Funke; Case, } 2016 . \\
\text { Melo; Duarte; Soares, } 2014 .\end{array}$ & Livros & $\begin{array}{l}\text { Microbiologia clínica; } \\
\text { farmacologia. } \\
\text { Antibióticos e } \\
\text { quimioterápicos. }\end{array}$ \\
\hline $\begin{array}{l}\text { Hachul et al.,2015; Panorama } \\
\text { Farmacêutico, 2017; Pêra, 2015; } \\
\text { Prevenção da infecção urinária } \\
\text { hospitalar...., } 2013 .\end{array}$ & $\begin{array}{l}\text { Outros (editorial, } \\
\text { informativo, } \\
\text { manual). }\end{array}$ & $\begin{array}{l}\text { Educação em saúde; } \\
\text { ITU; antibióticos; } \\
\text { Infecção hospitalar. }\end{array}$ \\
\hline
\end{tabular}


As infecções do trato urinário (ITU's) são causadas principalmente por bactérias

da Família Enterobacteriaceae, e acometem as mulheres com mais frequência. A uretra feminina é mais curta e está mais próxima ao ânus, facilitando a proliferação de bactérias mais facilmente. Contudo, os homens também são afetados, mas com menor frequência, pois sua uretra é mais longa do que a da mulher (MOURA; FERNANDES, 2010).

É importante lembrar que a infecção urinária ocorre em diferentes condições, desde uma uretrite a uma pielonefrite. A princípio tem-se uma inflamação da uretra (uretrite), e quando não tratada, inicialmente, essa inflamação atinge a bexiga (cistite). A pielonefrite é um risco mais importante nessa infecção. Os micro-organismos atingem os ureteres, acometendo os rins, ocorre septicemia e até finalmente morte (ZHONG et al., 2011; DREKONJA; JOHNSON, 2008).

Sendo assim, a infecção urinária pode ser sintomática ou assintomática e sua localização é classificada como alta ou baixa, portanto, a infecção urinária pode comprometer somente o trato urinário baixo, caracterizando o diagnóstico de cistite, ou afetar simultaneamente o trato urinário inferior e o superior, configurando infecção urinária alta, também denominada de pielonefrite (MOURA; FERNANDES, 2010; TORTORA, FUNKE; CASE, 2016).

A infecção do trato urinário baixo (cistite) apresenta-se habitualmente com disúria, urgência miccional, polaciúria, nictúria e dor suprapúbica. A febre nas infecções baixas não é um sintoma usual. A urina pode-se apresentar turva, pela presença de piúria, ou avermelhada devido ao processo inflamatório com presença de sangue. E a infecção do trato urinário alto (pielonefrite), se inicia habitualmente com o quadro de cistite, sendo frequentemente acompanhada de febre elevada, geralmente superior a $38^{\circ} \mathrm{C}$, associada a calafrios e dor lombar uni ou bilateral estando presente na maioria dos casos de pielonefrite (TORTORA, FUNKE; CASE, 2016).

Conforme citado por Roriz Filho et al. (2010), nos Estados Unidos da América, a incidência anual de ITU's em mulheres é de 12\%, cerca de 1/3 das mulheres são acometidas por um episódio de infecção urinária. Os casos de cistite acometem 0,70\% episódios por pessoa/ano entre as mulheres jovens, com possibilidade de recorrência dentro de seis meses em aproximadamente 25\% delas, podendo ainda evoluir para pielonefrite numa proporção estimada, de um caso para cada 28 cistites. Isso acontece 
devido ao tratamento inadequado, pois a estimativa de mulheres que recebem tratamento adequado é de aproximadamente 44\%, dentro de 12 meses. Em homens americanos, a incidência de infecção urinária é bem menor, apenas $20 \%$ e estima-se que em média ocorram anualmente, cinco a oito casos de cistite por 10.000 homens a cada ano. Em sua maioria, esses são resultantes de fatores obstrutivos (malformações, cálculos), diabetes mellitus e rim policístico (RORIZ FILHO et al., 2010)

A infecção urinária é definida pela presença de bactéria na urina tendo como limite mínimo de $10^{5}$ UFC. $\mathrm{mL}^{-1}$ de urina, colhida em jato médio e de maneira asséptica. E os exames complementares que podem ser úteis para o diagnóstico de infecção urinária são: urina de rotina, urocultura, antibiograma, hemocultura e exames de imagem (TORTORA, FUNKE; CASE, 2016).

O principal micro-organismo causador de infecção urinária é a Escherichia coli, atingindo cerca de $90 \%$ da população em geral. É pertencente à Família Enterobacteriaceae, a qual apresenta diversas espécies patogênicas. São bactérias gramnegativas em formato de bastonetes, possuindo vários flagelos em volta da célula (peritríqueos) (TORTORA; FUNKE; CASE, 2016). A E. coli foi inicialmente descrita no final do século XIX como Bacterium coli por ser colonizadora do intestino humano, logo após o nascimento, permanecendo por toda a vida. Além da E. coli, outros microorganismos da Família Enterobacteriaceae podem causar infecções urinárias, pertencentes aos gêneros: Shigella, Klebsiella, Proteus, Yersinia, Salmonella, Enterobacter e Serratia (DUQUE, 2013).

É de conhecimento geral que essas bactérias possuem em seu genoma alguns genes ligados a fatores de virulência. Linhagens uropatôgenicas de $E$. coli por ação das fímbrias que se ligam a receptores específicos presentes nos tecidos epiteliais iniciam as etapas de colonização do trato urinário (BARBERINO, 2013).

Os genes de resistência antimicrobiana estão, em geral, localizados em plasmídeos. A transferência de material genético na qual as bactérias podem ficar resistentes pode se dar por meio de três mecanismos: transformação: ocorre quando a bactéria adquire DNA livre, que contém genes de resistência e o incorpora no seu próprio genoma; transdução: ocorre quando a bactéria atua como hospedeiro de um vírus bacteriófago, o qual transmite genes de resistência durante seu ciclo reprodutivo e, conjugação: pela transmissão de elementos de resistência, tais elementos são conhecidos 
como plasmídeos, que podem conter genes de resistência a antibióticos e existir livremente no organismo, ou ainda integrar-se com o DNA cromossômico bacteriano (REIS et al., 2017).

O aparecimento de bactérias resistentes a antibióticos pode ser considerado como uma manifestação natural por adaptação genética de organismos a mudanças em seu meio ambiente. Uma vez que o tempo de duplicação da Escherichia coli pode ser apenas de 20 minutos, há possibilidade de serem produzidas muitas gerações em apenas algumas horas (REIS et al., 2017). Portanto, bactérias que antes não causavam doenças podem vir a causar infecção urinária pela aquisição de genes de resistência. Face ao exposto, tem-se a certeza de que o tratamento hoje em dia é difícil, pois a resistência bacteriana tornou-se um grande problema de saúde pública em escala mundial, representando uma ameaça para a humanidade. As infecções provocam $25 \%$ das mortes no mundo, sendo que as infecções urinárias em hospitais representam cerca de $40 \%$ devido ao uso de cateteres urinários que aumenta diariamente em até $5 \%$ o risco de infecção, e assim aumentando o número de infecções urinárias em até 95\% (OLIVEIRA et al., 2014).

No âmbito das prescrições de antimicrobianos, mais de 50\% são inapropriadas, dois terços dos antimicrobianos são usados sem prescrição médica em muitos países, $50 \%$ dos consumidores compram os medicamentos para um dia de tratamento e $90 \%$ dos consumidores utilizam os medicamentos apenas em três dias. Considera-se, portanto, que os antibióticos devem ser prescritos e administrados de forma racional, com base em um diagnóstico concreto e não apenas em dados epidemiológicos de determinados agentes etiológicos responsáveis por infecções (PREVENÇÃO..., 2013; GOLL; FARIA, 2013).

Com base em dados de pesquisa relativas a antibióticos e resistência bacteriana de 7560 exames de urocultura, em nível hospitalar, verificou-se positividade para ITU's em $90 \%$ do total de exames laboratoriais realizados (KADOSAKI; SOUZA; BORGES, 2012). Relativamente aos resultados dos testes de susceptibilidade para a bactéria mais frequente, a $E$. coli representou $80,4 \%$ dos isolados bacterianos.. A Ampicilina e Amoxicilina foram os antibióticos com maior taxa de resistência antimicrobiana. Já os antibióticos Amoxicilina/Ácido Clavulânico tiveram níveis de 
resistência intermediária. Para Ciprofloxacina, houve uma prevalência preocupante de 5,3\% em linhagens resistentes (KADOSAKI; SOUZA; BORGES, 2012).

Dados de pesquisa realizada em Lisboa (Portugal) a partir de comparação de resultados de susceptibilidade das linhagens de $E$. coli isoladas em 2008 com os dados de 2010 (Quadro 2) indicaram um aumento da resistência a todos os antibióticos estudados, com exceção da Cefuroxima que apresentou uma diminuição de 4,5\% para 2,3\% (DIAS; MONTEIRO; MENEZES, 2010).

QUADRO 2 Antibióticos mais usados em tratamento para cistites em Lisboa, Portugal (2008/2010)

\begin{tabular}{|c|c|c|}
\hline Antibióticos & $\begin{array}{c}\mathbf{2 0 0 8} \\
\text { (\% de resistência } \\
\text { antimicrobiana) }\end{array}$ & $\begin{array}{c}\mathbf{2 0 1 0} \\
\text { (\%de resistência } \\
\text { antimicrobiana) }\end{array}$ \\
\hline Ciprofloxacina & $8,2 \%$ & $16,1 \%$ \\
\hline Amoxicilina & $37,9 \%$ & $44,8 \%$ \\
\hline Trimetropim/Sulfametoxazol & $23,5 \%$ & $26,1 \%$ \\
\hline Amoxicilina/Ácido clavulânico & $1,2 \%$ & $2,8 \%$ \\
\hline Nitrofurantoína & $2,1 \%$ & $3,3 \%$ \\
\hline Fosfomicina & $0,5 \%$ & $0,9 \%$ \\
\hline
\end{tabular}

Adaptado de Narciso et al. (2011)

Adaptado de Narciso et al. (2011) mais usados em tratamento para cistites em Lisboa, Portugal (2008/2010)

Com base nas pesquisas citadas, pode-se considerar que a taxa de resistência antimicrobiana está aumentando gradativamente com passar dos anos. Mesmo com receita médica, ainda continua sendo uma situação alarmante e inclui todas as classes de antibióticos. Nesse sentido, torna-se essencial desenvolver novos métodos de diagnóstico 
e tratamento das doenças infecciosas, bem como educar médicos e leigos sobre o uso criterioso desses medicamentos (PREVENÇÃO..., 2013; DIAS; MONTEIRO; MENEZES, 2010).

Sabe-se que para minimizar os problemas relacionados ao uso inadequado de antibióticos, seria necessário esclarecer as dúvidas dos pacientes, tais como: duração do tratamento e do intervalo entre as administrações, garantindo que haja adesão completa ao tratamento para que não ocorra a diminuição da concentração plasmática. Por isso, considera-se a prática da atenção farmacêutica como essencial para o entendimento do tratamento pelo paciente (RODRIGUEZ et al., 2017).

As infecções repetidas ocasionam um aumento excessivo no uso de antibióticos. Existem cerca de 150 milhões de casos por ano de infecção urinária. Outras formas de prevenção devem ser utilizadas para melhorar a qualidade de vida das pessoas (HACHUL et al., 2015). Por outro lado, a produção de antibióticos nos últimos tempos tem sido reduzida, o mais recente descoberto é a Pseudouridimicina, indicado para um amplo aspecto de bactérias multirresistentes (PANORAMA...2017).

A fruta cranberry é rica em proantocianidinas, substâncias que inibem a adesão das bactérias na parede da bexiga, incluindo a Escherichia coli (ALMEIDA, 2014). Há indícios de redução da taxa de infecções e do uso indiscriminado de antibióticos (NELIUS et al., 2013; ALMEIDA, 2014). Portanto, essa fruta tem sido indicada para indivíduos que já sofreram infecção urinária e que têm probabilidade de reincidência. 


\section{Considerações Finais}

Neste artigo destacou-se a problemática da infecção urinária. Essa doença foi escolhida para a pesquisa devido ao fato que ela é uma infecção que se repete e acomete, principalmente, mulheres. A causa mais comum é a contaminação por Escherichia coli. Além disso, a resistência bacteriana a antimicrobianos constitui-se em um grande problema de saúde mundial e um desafio a ser vencido.

Novos antimicrobianos precisam ser desenvolvidos para ampliar as possibilidades de cura de infecções recorrentes, especialmente as infecções urinárias. Alimentos contendo substâncias protetoras do uroepitélio estão entre as alternativas profiláticas mais recentes, viáveis, naturais e eficazes para reduzir a reincidência de infecções urinárias em mulheres.

\section{Referências}

ALMEIDA, J.M.P. Aplicações farmacêuticas das proantocianidinas. 2014. 62 f. Dissertação (Mestrado Integrado em Ciências Farmaceuticas) - Instituto Superior de Ciências da Saúde Egas Moniz, Portugal, 2014. Disponível em: < https://comum.rcaap.pt/bitstream/10400.26/13050/1/Almeida,\%20Joana\%20Marques \%20Peras\%20de.pdf>. Acesso em: 20 fev. 2018.

BARBERINO, M.G.M. de A. Distribuição clonal de Escherichia coli isoladas em infecções do trato urinário adquiridas na comunidade no período de 2001 a 2009 na cidade de Salvador-Bahia. 2013. Tese 115 f. Tese (Doutorado em Biotecnologia em Saúde e Medicina Investigativa) - Fundação Oswaldo Cruz, Centro de Pesquisas Gonçalo Moniz, Salvador, 2013. Disponível em:

< https://www.arca.fiocruz.br/handle/icict/7314>. Acesso em: 18 dez. 2017.

CAPES - Coordenação de Aperfeiçoamento de Pessoal de Nível Superior. Disponível em: < http://www.periodicos.capes.gov.br/>. Acesso em: 05 fev.2017.

CUNHA, A.J.; VEBER, L.M. Perfil e nível de resistência bacteriana em amostras isoladas de infecções do trato urinário de clientes de um laboratório de análises clínicas. 2011. 35f. Trabalho de Conclusão de Curso (Pós-graduação em Doenças Parasitárias) - 
Centro de Ciências da Saúde - Universidade Regional de Blumenau, SC, 2011. Disponível em:

<www.uniedu.sed.sc.gov.br/wp-content/uploads/2013/10/Leda-Maria-Veber.pdf>.

Acesso em: 20 mar 2018.

DIAS, M.; MONTEIRO, M.S.; MENEZES, M.F. Antibióticos e resistência bacteriana, Velhas Questões, Novos desafios. Cad Otorrino, n.1, p.1-10, 2010.

DREKONJA, D.M.; JOHNSON, J.R. Urinary tract infections. Primary care, v. 35, n. 2, p. 345-67, 2008.

DUQUE, E.M. A importância da Escherichia coli como agente etiológico responsável pela infecção do trato urinário. 2013. Monografia 34 f. (Programa de Pós-Graduação em Microbiologia do Instituto de Ciências Biológicas) - Universidade Federal de Minas Gerais, 2013. Disponível em: < http://www.bibliotecadigital.ufmg.br/dspace/bitstream/handle/1843/BUBD9EFJ99/monografia edson.pdf?sequence=1>. Acesso em: 26 fev.2018.

GOLL, A.S.; FARIA, M.G.I. Resistência bacteriana como consequência do uso inadequado de antibióticos. Braz. J Surg Clin Res., v.5, n.1., p. 69-72, 2014.

GUIMARÃES, D.O.; MOMESSO, L.S.; PUPO, M.T. Antibióticos: importância terapêutica e perspectivas para a descoberta e desenvolvimento de novos agentes. Quimica Nova, v.33, n.3, p.667-679, 2010.

HACHUL, M. et al. Infecção do Trato urinário complicada. Universidade de Santo Amaro - São Paulo. Grupo Editorial Moreira Junior. 2015. Disponível em: $<$ http://www.moreirajr.com.br/revistas.asp? fase=r003\&id materia=6207 >. Acesso em: 26 mar. 2018.

KADOSAKI, L.L.; SOUZA, S.F.; BORGES, J.C.M. Análise do uso e da resistência bacteriana aos antimicrobianos em nível hospitalar. Rev. Bras. Farmácia v. 93, n., p.128135, 2012.

MELO, V.V.; DUARTE, I.P.; SOARES, A.Q. Guia de antimicrobianos. 1. ed. Goiás: Residência Multiprofissional em Saúde - Hospital das Clínicas - Universidade Federal de

Goiás.

2012.

58p.

Disponível

em: 
$<$ https://farmacia.hc.ufg.br/up/734/o/Guia de Antimicrobianos do HCUFG.pdf?1409055717 >. Acesso em: 22 fev. 2018.

MOURA, L.B.; FERNANDES, M.G. A Incidência de infecções urinárias causadas por E. coli. Revista Olhar Cientifico, v.1, n.2, p. 411-416, 2010.

NARCISO, A. et al. Susceptibilidade aos antibióticos de bactérias responsáveis por cistites não complicadas: estudo comparativo dos isolados de 2008 e 2010. Acta Urológica, n. 1, p.16-21, 2011.

NELIUS, T. et al. Immune-based Treatment Strategies for Patients with Recurrent Urinary Tract Infections - Where Are We? In: Recent Advances in the Field of Urinary Tract Infections. Intech - Open Science Open Mind. 2013, cap. 8, p. 1-15. Disponível em: https://www.intechopen.com/books/recent-advances-in-the-field-ofurinary-tract-infections >. Acesso em: 04 mar. 2018.

OLIVEIRA, A.L.D. et al. Mecanismo de resistência bacteriana a antibióticos na infecção urinária. Revista UNINGÁ Review, v.20, n.3, p. 65-71, 2014.

PANORAMA FARMACÊUTICO. Brasil. Novo antibiótico é descoberto no solo. Disponível em: <https://panoramafarmaceutico.com.br/2017/06/29/novo-antibioticoe-descoberto-no-solo/>. Acesso em: 26 mar $/ 2018$.

PÊRA, M.C.S.M. Terapêutica antibiótica empírica em infecções adquiridas na comunidade. 2015. 107 f. Dissertação (Mestrado em Ciências Farmacêuticas) Instituto Superior de Ciências da Saúde Egas Moniz, Portugal. 2015. Disponível em: $<$ https://comum.rcaap.pt/bitstream/10400.26/11330/1/P\%C3\%AAra\%2C\%20Mariana \%20C\%C3\%A1ssio\%20de\%20Sousa\%20Mergulh\%C3\%A3o.pdf>. Acesso em: 14 mar. 2018.

PREVENÇÃO DA INFECÇÃO URINÁRIA HOSPITALAR...... Coordenação de Controle de Infeç̧ão Hospitalar. Rio de Janeiro. Universidade Federal do Rio de Janeiro. 2013. Disponível em: < http://www.hucff.ufrj.br/download-dearquivos/category/9-ccih?download=265:orientacoes-e-recomendacoes. $>$. Acesso em: 20 fev.2018.

RANG, H.P. et al. Range छ Dale Farmacologia. (Trad.)7. ed. Rio de Janeiro: Elsevier, 2012.768p. 
REIS, A.L.O. et al. Escherichia Coli na infecção do trato urinário em mulheres. Braz. J Surg Clin Res, v. 20, n.2, p.122-127, 2017.

RODRIGUES, A.P. et al. Análise das prescrições de antibióticos. Revista Interdisciplinar, v. 10, n. 4, p. 69-76, 2017.

RORIZ FILHO, J.S. et al. Infecção do trato urinário. Ribeirão Preto-SP: Hospital Estadual de Ribeirão Preto. Medicina (Ribeirão Preto) v.43, n.2, p 118-25, 2010.

Doi: https://doi.org/10.11606/issn.2176-7262.v43i2p118-125

TAVARES, W. Antibióticos e quimioterápicos para o clínico. 3.ed. São Paulo: Atheneu, 2014. $746 \mathrm{p}$.

TORTORA, G.J.; FUNKE, B.R.; CASE, C.L. Microbiologia. (Trad. por Roberto Marchiori Martins). 12 ed. Porto Alegre: Artmed, 2016

ZHONG, Y.H. et al. Effectiveness and safety of patient initiated single-dose versus continuous low-dose antibiotic prophylaxis for recurrent urinary tract infections in postmenopausal women: a randomized controlled study. J Int Med Res. v.39, n.6, p. 2335-43, 2011. 